\title{
A proposal for a brief-term post-adoption intervention in the attachment-perspective: a single case study with a late-adopted child and his adoptive mother
}

\author{
Cecilia Serena Pace, ${ }^{1}$ Ester D’Onofrio, ${ }^{2}$ Viviana Guerriero, ${ }^{2}$ Giulio Cesare Zavattinii ${ }^{2}$ \\ ${ }^{1}$ Department of Educational Science, University of Genoa, Genoa; ${ }^{2}$ Department of Clinic and Dynamic Psychology, La Sapienza \\ University of Rome, Rome, Italy
}

\begin{abstract}
A growing body of attachment literature has focused on bridging the gap between research and clinical applications, even in clinical work with adoptive families. A brief-term clinical intervention focused on a multi-method assessment of attachment relationships and representations was performed in the first year after placement. This single case study aimed at analysing the attachment outcomes, through a long-term follow-up, both for the adoptive mother and her late-adopted son. We assumed that this five-session attachmentoriented intervention could help the mother enhance her sensitivity skills and her ability to understand both her own past attachment experiences and her child's insecure attachment as a consequence of the failures of his previous experiences of care, supporting her sixyear old child in acquiring a positive image of himself and of others and the security of the caregiver's availability up to adolescence.
\end{abstract}

Key words: Brief-term post-adoption; Attachment-perspective; Late-adopted child.

\section{Introduction}

Families who adopt children - in particular older ones - often have to face their damaged attachment representations due to neglect, abandonment, and loss often experienced in their pre-adoption lives (Dozier \& Rutter, 2008; Pace, Zavattini, \& Tambelli, 2015). A 2009 meta-analysis showed that children adopted before 12 months of age were as securely attached as their non-adopted peers, whereas

Correspondence: Cecilia Serena Pace, Department of Educational Science, University of Genoa, Corso Andrea Podestà 2, 16128 Genoa, Italy.

Tel: +39.010.20953502/03. - Fax: +39.010 .20953506 .

E-mail: cecilia.pace@unige.it

Citation: Pace, C.S., D’Onofrio, E., Guerriero, V., \& Zavattini, G.C. (2016). A proposal for a brief-term post-adoption intervention in the attachment-perspective: a single case study with a lateadopted child and his adoptive mother. Research in Psychotherapy: Psychopathology, Process and Outcome, 19(1):31-40. doi: 10.4081/ripppo.2016.197

Received for publication: 15 September 2015.

Revision received: 15 November 2015.

Accepted for publication: 17 December 2015.

This work is licensed under a Creative Commons Attribution NonCommercial 4.0 License (CC BY-NC 4.0).

CCopyright C.S. Pace et al., 2016

Licensee PAGEPress, Italy

Research in Psychotherapy:

Psychopathology, Process and Outcome 2016; 19:31-40

doi:10.4081/ripppo.2016.197 children adopted after their first birthday showed less attachment security if compared with non-adopted children (van den Dries, Juffer, van IJzendoorn, \& Bakermans-Kranenburg, 2009). These data seem particularly interesting regarding adoptions in Italy if we look at the latest information provided by the Italian Adoption Commission (2014) indicating that almost $95 \%$ of the children adopted between 2000 and 2012 were placed after one year of life.

Globally adoption research, on the one hand, has pointed out that late-adopted children are at high risk for elevated rates of socio-emotional and behavioural difficulties, including insecure/disorganized attachment patterns and internalizing and externalizing behaviour problems; on the other hand, high resilience, capacity of recovery from early deprivation, ability to build positive representations of new caregivers, and earned attachment security emerged in adopted children and their adoptive families (Barone \& Lionetti, 2012; Bimmel, Juffer, van IJzendoorn, \& Bakermans-Kranenburg, 2003; Bakermans-Kranenburg, van Ijzendoorn, \& Juffer, 2003; Pace \& Zavattini, 2011; Pace, Cavanna, Velotti, \& Zavattini, 2014; Steele et al., 2008). Recent longitudinal attachmentbased studies on adoption and maternal sensitivity showed that more sensitive parenting -in infancy middle childhood, and/or adolescence- predicted continuity of secure attachment of adopted children from infancy to adolescence, less inhibited and delinquent behaviours in adolescence and secure attachment representations in young adulthood (Beijersbergen, Juffer, Bakermans-Kranenburg, \& van IJzendoorn, 2012; Pace, Di Folco, Guerriero, Santona, \& Terrone, 2015a; Schoenmaker et al., 2015a; van der Voort, Linting, Juffer, Bakermans-Kranenburg, \& van 
IJzendoorn, 2013; van der Voort et al., 2014). In addition, while secure adoptees showed a well-integrated response to infant distress in young adulthood, insecure adoptees showed a deactivating strategy, revealed by dissociation between experiential and physiological arousal (Schoenmaker et al., 2015b). Finally, no associations were found between early attachment security, attachment disorganization, maternal sensitivity and the diurnal cortisol curve of adoptees at 23 years old (van der Voort et al., 2014).

Moreover, literature on adoptive parents showed the protective role of the parents' secure attachment states of mind and their romantic relationships on the parenting functioning and stress, which in turn may influence child adaptation (Goldberg \& Smith, 2014; Grotevant \& McDermott, 2014; Lionetti, Pastore, \& Barone, 2015; Pace, Santona, Zavattini, \& Di Folco, 2014; Pace, Santona, Zavattini, \& Di Folco, 2015b; Palacios \& Brodzinsky, 2010; Salcuni, Miconi, Altoè, \& Moscardino, 2015). In recent years, several brief-term clinical interventions were developed for supporting the growing attachment bonds in adoptive and foster families, e.g. the Attachment and Biobehavioural Catch-up (Dozier et al., 2006), the VideoFeedback Intervention to Promote Positive Parenting (Juffer, Bakermans-Kranenburg, \& van IJzendoorn, 2005), the Parent-Child Interaction Therapy (Allen, Timmer, \& Urquiza, 2014), etc. As a recent review (Kerr \& Cossar, 2014) highlighted, these highly-structured interventions are aimed at increasing parental awareness of the impact of early maltreatment on child development and insecure/disorganized attachment, also improving parents' ability to recognize child's emotions and to adequately respond to them (Carnes-Holt, 2012; Holmes \& Silver, 2010). These interventions provide also parents with better theoretical understanding of attachment theory and a practical understanding of how children's attachment could influence the parent-child relationship (GurneySmith, Granger, Randle, \& Fletcher, 2010). In addition, many scholars and clinicians have pointed out the relevance of the clinical applications of attachment research assessments, like the Adult Attachment Interview, the Strange Situation Procedure, the Co-construction task, the Story Stem Assessment Profile (Main, Hesse, \& Goldwyn, 2008; Oppenheim \& Goldsmith, 2007; Steele \& Steele, 2008), etc., which were successfully utilized in clinical work with children and their families.

In this regard, Steele and colleagues (2007) used attachment theory and methods for the evaluation and treatment of an adopted child with a history of maltreatment, while Dozier, Grasso and Lindhiem (2007) used This Is My Baby Interview to clinically evaluate the parents' thoughts and feelings regarding the foster children and their interest in their enduring relationship. Attachment research assessments open a window into the inner world of the patients and their meaningful relationships, increasing the clinician's awareness of the patients' functioning of the attachment system, processes and defensive patterns, rather than the mere knowledge of the attachment classification of the patient (Salcuni, Di Riso, \& Lis, 2014; Slade, 2010).

Concerning adoption, Goldsmith (2007) suggested that an attachment assessment may help clinicians to sustain families in their first period after adoption, which is considered a high-risk phase regarding the building of attachment relationships in new adoptive families.

\section{Aim}

Our article is aimed at showing the clinical applications of attachment assessment in a brief-term post-adoption intervention throughout a single case study with a late-adopted child and his adoptive mother. The clinical work with the adoptive mother was mostly focused both on maternal sensitivity, defined in terms of perceiving and interpreting child signals in an accurate way (observing), and responding to these signals in an adequate and prompt way (reactions), and attachment states of mind, as the narrative representation of maternal internal working model. To our knowledge, this is the first post-adoption intervention that provided a multi-dimensional assessment of attachment of an adoptive dyad - including behavioural and narrative procedures, mother and child assessments, and maternal attachment representations both with respect to caregivers and couple relationship - together with a longterm follow-up.

\section{Methods}

\section{Patients' presentation}

The name of the late-adopted child is Kiwot. He was born in the Congo Republic and he was six years old when he was placed for international adoption. Before being adopted, Kiwot lost both his biological parents because of a viral disease when he was two years old and he had lived the following years in an institution together with his siblings. His adoptive mother, Johanna, was a 43 -year-old woman, good looking, belonging to the middle class. She graduated and works as a graphic designer. Johanna had been married for 12 years with Peter, lawyer, 46 years old, and the couple never had biological children. Kiwot was adopted together with his older sister, Meheret, while the youngest one, Semerat, remained in the country of origin due to a physical disease which made her unsuitable for adoption. Kiwot and his sister were adopted by Johanna and Peter through an Agency for International Adoption which had a cooperation agreement with the Clinical Center of the Department of Dynamic and Clinical Psychology of La Sapienza University of Rome, which was developing a brief-term attachment-oriented post-adoption intervention. Before the adoption, the Agency presented the opportunity to participate, after children's placement, in a brief intervention of five sessions focused on the mother-child relationship for supporting the early stages of adoption.

After one month and half from their arrival, Johanna 
called the Clinical Center and asked for being involved in the post-adoption intervention together with her younger son Kiwot, because Our relation is getting worst and worst. More the time goes away, more we become more distant than we were when we met.

\section{Measures}

A brief-term clinical attachment-oriented intervention, focused on a multi-method assessment of attachment relationships and representations, was performed. In contrast to the attachment-based interventions that are highly-structured types of intervention entirely based on the concepts of attachment theory, in the attachment-oriented (or informed) intervention the existing therapeutic modalities or social interventions incorporate concepts and knowledge from attachment theory and research (Holmes \& Farnfield, 2014). We used the following measures with Kiwot.

The Separation-Reunion Procedure (SRP; Cassidy, 1988; Main \& Cassidy, 1988) is a laboratory procedure based on the SSP (Ainsworth, Blehar, Waters, \& Wall, 1978) model and designed for classifying the attachment behavioural patterns shown by children at pre-school and school-age. In the SRP, the child experiences two separations from the mother and two reunions with her, both of which are coded. The first separation lasts for 10-15 minutes, the second for approximately 45-60 minutes (Pace \& Zavattini, 2011). The first coding comprises assigning scores on two scales: avoidance and security. The second coding classifies reunion behaviours into one of the following three main attachment patterns: secure (B), insecure/avoidant (A), insecure/ambivalent (C), when the child shows signs of passivity-immaturity and/or anger. In addition, one of the two secondary categories could also be assigned to reunion behaviour: insecure/controlling (D), and insecure-unclassifiable (U) pattern. In this study we focused the intervention on enhancing the quality of mother-child interactive behaviour using measures related to the attachment theory. In particular, the variables of separation and proximity were chosen taking into account both the specific pre-adoptive history of Kiwot, characterized by negative early experiences with his caregivers, and the event of adoption itself.

The Manchester Child Attachment Story Task (MCAST; Barone et al., 2009; Green, Stanley, Smith, \& Goldwyn, 2000) is a story completion task, which is used to classify the attachment narrative representations of children between the ages of four and eight years old. The assessment is organised into six stories to be completed. The four central stories are designed to activate the motivational system of attachment and they concern: nightmares, a knee injury, a stomachache, and getting lost in a shopping centre. Scores of 1-9 on 33 scales and a final classification - secure (B), avoidant (A), ambivalent (C), disorganized (D) - are then assigned to each story. From these codes, it is possible to add more scores from three global scales - coherence of mind, mentalization, and disorganization - and a final clas- sification - A, B, C and D - to the whole MCAST (Pace, Zavattini \& D'Alessio, 2012).

The Friend and Family Interview (FFI; Pace, 2014; Steele, Steele, \& Kriss, 2009) is a semi-structured interview informed by, yet distinct from, the Adult Attachment Interview (AAI; Main et al., 2008) designed to assess the attachment representations of adolescents from 11 to 17 years old. Interviews are video-recorded and transcribed verbatim. The FFI's coding system comprises eight scales, each including subscales, scored on a 7-point scale from 1 (no evidence) to 4 (marked evidence) including midpoints: coherence, reflective functioning, evidence of secure base, evidence of self-esteem, peer relations, sibling relations, anxieties and defence, and differentiation of parental representations. The interview also includes the following global attachment classifications: secure, insecure-dismissing, insecure-preoccupied, and finally, insecure-disorganized.

We administered the following measures to Johanna. The AAI (Main, Goldwyn, \& Hesse, 2002) is an hour-long semi-structured interview with 20 questions to evaluate and classify adults' state of mind with respect to attachment in their early attachment experiences. AAI transcripts are valued on ordinal scales of nine points each to assess possible past experiences with attachment figures in infancy, and current states of mind. Then the AAIs are assigned to one of the following main classifications: secure/autonomous (F/A); dismissing (Ds); preoccupied-entangled (E); one of two other transversal categories, unresolved loss or trauma (U) and cannot classify (CC), can also be added.

The Current Relationship Interview (CRI; Crowell \& Owens, 1996) is a semi-structured interview protocol based on the AAI model, intended to assess state of mind with respect to attachment in adult romantic relationships. The structure of the CRI is analogous to that of the AAI, however the questions deal with the nature of adult relationships. The coding system is also similar to that of the AAI because interview transcripts are used and analysed on three sets of scales: participant's history; partner and participant variables, and current states of mind. Classification in terms of attachment categories - Secure (S), Dismissing (D), Preoccupied (P), Unresolved (U) - is based on the scores for each scale and on an overall assessment of the interview (Pace et al., 2015b).

Assuming that the quality of the marital relationship plays a very important role in the child's attachment patterns and adaptation, this intervention paid attention to couple attachment representations, considered as a protective or risk factor from the parental stress during the transition to parenthood in adoptive parents (Pace et al., 2014, 2015b; Salcuni et al., 2015).

\section{Procedure}

A brief-term intervention was scheduled, conducted in the seven months after adoption. It comprised the following five sessions. 
One assessment session, two months after adoption, in which Kiwot and his mother were observed in the SRP1 and Johanna was administered the AAI. Before the SRP, the clinician and the mother had agreed that whether Kiwot had experienced excessive distress for the separation, the procedure would be interrupted.

Two intervention sessions, monthly: the first focused on the video previously recorded and the last on the maternal attachment states of mind.

Another assessment session, after two months, in which Kiwot and his mother were again observed in the SRP-2. Again, the procedure would be completed only whether Kiwot was able to tolerate the separation without extreme anxiety. Moreover, the MCAST was administered to Kiwot and the CRI to Johanna.

A last feedback session, a few months after the previous one, focused on the clinical tools used in the previous session.

The assessments sessions involved both mother and child, while the others were conducted only with Johanna. After seven years, when Kiwot was 13 years old, the dyad was contacted for a long-term follow-up. At this time the FFI was administered to Kiwot and Johanna was again interviewed with the AAI. Table 1 synthesises the whole procedure.
The clinician had a psychodynamically-oriented background with several attachment trainings, together with a solid expertise with adoptive families. All the measures SRP 1-2, AAI 1-2, MCAST, CRI, FFI - were coded by two reliable judges trained in the specific coding systems: the intervener plus another blinded coder. The inter-rater agreement was 100\%. During the seven years which passed before the last long-term follow up, none members of this adoptive family never contacted the clinician or other mental health services. Sometimes Johanna and Peter attended seminars on international adoption issues -such as bi-cultural identity of adoptees, relationships with birth families, etc., organized by the Agency for International Adoption.

\section{Results}

\section{The initial assessment: the first session}

\section{Separation-Reunion Procedure-1}

At the first assessment session, Kiwot was classified as insecure - avoidant (Table 2) in the SRP, which is assigned when the child tends to ignore the mother's presence and remains concentrated on his own activi-

Table 1. Brief-term attachment-informed post-adoption intervention.

\begin{tabular}{lccc}
\hline Sessions & & Child & Mother \\
\hline $1^{\text {st }}$ & Assessment 1 & SRP-1 & AAI-1 \\
\hline $2^{\text {nd }}$ & Intervention 1 & Focus on SRP-1 \\
\hline $3^{\text {rd }}$ & Intervention 2 & Focus on AAI-1 \\
\hline $4^{\text {th }}$ & Assessment 2 & CRI \\
\hline $5^{\text {th }}$ & Feedback & SRP-2, MCAST & Focus on SRP-2, MCAST, CRI \\
\hline
\end{tabular}

Long-term follow-up

FFI

AAI-2

SRP-1, Separation-Reunion Procedure-1; AAI-1, Adult Attachment Interview-1; SRP-2, Separation-Reunion Procedure-2; MCAST, Manchester Child Attachment Story Task; CRI, Current Relationship Interview; FFI, Friend and Family Interview; AAI-2, Adult Attachment Interview-2.

Table 2. Summing of scorings and classifications of Kiwot and Johanna's attachment assessments.

\begin{tabular}{|c|c|c|c|c|c|c|}
\hline & & & SRP-1 (range) & SRP-2 (range) & MCAST (range) & FFI (range) \\
\hline \multirow[t]{7}{*}{ Kiwot } & Scorings & Security & $4(1-9)$ & $6.5(1-9)$ & & $4(1-4)$ \\
\hline & & Avoidance & $4(1-7)$ & $2(1-7)$ & & $2(1-4)$ \\
\hline & & Coherence & & & $5(1-9)$ & $3.8(1-4)$ \\
\hline & & Disorganization & & & $4(1-9)$ & $1(1-4)$ \\
\hline & & Mentalizing & & & $1(0-3)$ & \\
\hline & Classifications & & Avoidant & Secure & Secure/disorganized & Secure \\
\hline & & & AAI-1 & CRI & AAI-2 & \\
\hline \multirow[t]{3}{*}{ Johanna } & Scorings (1-9) & Coherence (1-9) & 5.5 & 6.5 & 7 & \\
\hline & & Unresolved loss (1-9) & 6 & 1 & 1 & \\
\hline & Classifications & & $U / F 4 b$ & Secure & $F 3 b$ & \\
\hline
\end{tabular}

SRP-1, Separation-Reunion Procedure-1; SRP-2, Separation-Reunion Procedure-2; MCAST, Manchester Child Attachment Story Task; FFI, Friend and Family Interview; AAI-1, Adult Attachment Interview-1; CRI, Current Relationship Interview; AAI-2, Adult Attachment Interview-2. 
ties. Although Kiwot appeared a bit bothered during the two separation episodes from his mother, complaining and asking for her to the stranger, when Johanna came back to the room the son did not leave emerge his emotions. During the first reunion, when the mother came back and said hello to him, Kiwot remained seated, with his gaze focused on the playmobiles. Johanna approached him at the table, asked him for something, and kissed him. Kiwot did not reply, but after a while, involved his mother in the play. Also at the second reunion, although the mother approached him warmly, Kiwot did not seem interested in these effusions, but he appeared more focused on the playful activities. The avoidant classification indicates an underlying deactivating attachment pattern in which a child, when distressed, tends to minimise attachment needs, feeling and behaviours, moving his attention away from the caregiver and towards activities.

\section{Adult Attachment Interview-1}

The AAI of Johanna was classified as unresolved/secure, specifically as $U / F 4 b$ (Table 2 ). The $U$ classification of Johanna's AAI was attributed to the lack of resolution with respect to her mother's loss. She showed some lapses of monitoring both of the discourse, such as prolonged silence when she talked about her mother's loss, and reasoning - such as speaking about her mother, who died more than 10 years ago, using present tense: My mother is a brilliant woman, she is very bright. Moreover, she reported extreme behavioural reactions after her mother's loss, such as depressive symptoms. The F4 sub-category specifically detects individual with a secure attachment state of mind, strong valuing of relationships, with some accompanying preoccupation with attachment figures, with separation or with past trauma expressed through passivity of discourse or current anger during the interview. Finally, the $b$ indicates individuals with a difficult childhood that may include negative relationship with caregiver and traumatic experiences, such as physical abuse, which directly preoccupy attention. Indeed Johanna experienced a very troubled relationship with an aggressive and violent father. However, she talked about her childhood attachment bonds with coherence, lucidity and clarity, showing a lucid awareness of the influence that the relationships with their parents had on the development of her adult personality. She was very open and spontaneous in communicating emotions related to the relational experiences lived as a child. Moreover, despite her unfavourable relationship with an insensitive and unresponsive father, she appeared quite objective and partially forgiving towards him, without showing an excessive and angry involvement. She said: My father was aggressive, probably he did so because, as my aunt, my father's sister told me, my father, in turn, when he was a child he was severely and harshly beaten from his father who was very authoritarian and coercive.

\section{The core of the brief clinical intervention: second and third sessions}

The second session was focused on the improvement of the maternal sensitivity through the reviewing of the videos of the mother-child interactions during the episodes of separation and reunion. This session was developed by encouraging Johanna to pay attention to her child's needs and to his minimal signals of attachment, helping her to interpret the child's signals and to provide a proper and attuned response to his needs.

In the first part of the video, the clinician showed the mother the first few minutes when the mother and child were in the same room and Kiwot was playing alone. The mother tried to capture the attention of the child without success and the video showed how the mother seemed to be stressed probably as a result of this lack of interaction. In fact, when the clinician asked Johanna What's going on in the video?, she answered Kiwot is playing alone and I cannot involve him in any way and when the clinician asked What do you think your child is feeling right now? she answered I believe Kiwot is fine but when he asked What did you feel? she admitted that she felt a great sense of frustration. The clinician explained to her that the avoidant pattern enacted by Kiwot is characterized by minimizing attachment needs and feelings caused by having experienced rejecting parenting.

The second video that was shown to Johanna portrayed the moment of reunion in which Kiwot did not show displays of affection when his mother came back into the room and he still kept playing. Similarly, the clinician asked the mother what she thought Kiwot was feeling and what she was feeling herself. Johanna replied Kiwot seems indifferent to what is happening... I do not understand why he behaves in this way but maybe it's a normal thing and I was quiet because I saw him playing calmly but inside me I was a little sad, because as a mother I hoped he was a more affectionate child. Explaining to the mother that avoidant children suffer with separation from the attachment figure, express their disappoint and distress by moving away from the parents rather than toward them when they were reunited with the caregiver, provided her a clear key to the behaviour of her child, trying to facilitate her to get in touch with him in a more understanding way.

In line with this consideration, the pre-adoption history was discussed pointing out how the previous negative experience affected Kiwot's relational strategy. The clinician supposed that Kiwot, who was early abandoned and then institutionalised as a child, was deprived of a stable attachment figure and this could have negatively affected the way in which he interacts with others and how he expects others to respond to him. The child probably developed an image of the self as unworthy of love and lack of confidence towards the attachment figure. In other words, his inner message was I rejected other before other rejects $m e !$ (Howe, 1998). In addition, the clinician offered to Jo- 
hanna some adaptive strategies and suggestions. In particular, she suggested to the mother to communicate to the child the idea to have the child in mind even she was not physically present. She said to the mother that it is important to think about the emotional needs of the child even when they are not compelling. In this way the child may start feeling protected and loved by his mother, even when they are not close.

The next session was focused on the mother's AAI, which had highlighted a lack of resolution of her mother's loss. Johanna admitted that the interview gave her the opportunity to talk about the memories and feelings related to the death of her mother. In this regard she said: Talking about the loss of my mother was not easy and I think I still have a burden on the stomach even though many years have passed. The session with the clinician focused on the issues of attachment also revealed some questions she had about her own relationships with attachment figures. In particular, Johanna wondered how the loss of my mother could influence my relationship with Kiwot?. The clinician therefore explained to her that not the loss in itself but the inability to get in touch with her feelings of sadness and pain for the mother's loss may be an obstacle to come into contact with her own emotions related to the difficulties with Kiwot. This in turn could adversely affect her parenting experiences: these emotional difficulties would lead her to feel very preoccupied when Kiwot did not answer in the way she was expecting, negatively influencing her parental experience.

\section{A new assessment: the fourth session}

\section{Separation-Reunion Procedure-2}

After three months, attachment behavioural patterns of Kiwot were again assessed by the SRP. Globally Kiwot showed pleasure at the reunion with his mother, accepted and responded willingly to her mother's signals of warmth and questions, and sometimes he directly searched for contact with her affectionately and started conversations with her about what happened when she was outside the room. Both reunions were marked by a very calm and relaxed atmosphere and the widespread presence of visual and verbal exchanges between mother and child. Overall Kiwot and Johanna demonstrated a good dyadic tune, pleasure and comfort in conversing together. In the second reunion, affectionate exchanges between mother and child, as a mutual embrace were highlighted. His attachment classification changed from insecure/avoidant to a secure one, showing a more relaxed and accepting behaviour in the child and more pleasure and love in the dyadic interaction (Table 2).

\section{Manchester Child Attachment Story Task}

The earned security (Pace et al., 2012) in the behavioural pattern of Kiwot was supported by the secure attachment representation revealed by the MCAST classified as secure with mild index of disorganization (Table 2). A secure classification is assigned when the strategy of attachment is characterized by the representation of an interaction of proximity with the caregiver that brings an assuagement of the discomfort. In each vignette, Kiwot used an interpersonal strategy in order to solve the attachment distress themes: every time the child-doll asked mum-doll for help, and she was able to provide a sensitive and warm response, which can soothe him. For example, in the nightmare vignette, mum-doll reached for child-doll to his bed (he called her) and said: Mum is here. Don't worry, sleep quiet, sleep well, sleep peaceful. However mild indexes of disorganization emerged such as rarely violently bumping or dropping dolls on occasion and fear expressions. Overall, Kiwot looked collaboratively and favourably involved in the MCAST. He listened carefully to the stories. He was focused on the task and timely responded. Sometimes his words were not so clear, probably due to the ongoing learning of Italian language.

\section{Current Relationship Interview}

The CRI of Johanna was classified as secure with respect to attachment. Indeed she talked about her-partner relationship with respect and affection, reporting to feel respect and trust towards him. She was able to provide a credible and fluid narration of the current relationship with the partner, although it was not particularly rich with specific episodes. She showed good reflective functioning and ability to understanding the mutual interchange between her and her husband as follows: Peter is always able to trigger the most positive part of me better than I do. However I am used to helping him as he wishes. The intimate communication, the emotional affection, the intellectual exchanges, together with the appreciation of their relationship were the most valued characteristics expressed in Johanna's CRI. Sometimes Johanna was even able to detect some negative aspects in the relationship with Peter, such as his difficulty with managing her disease and negative individual characteristics such as his over-protectiveness towards their late-adopted children, but she talked about them in a balanced and objective manner.

\section{The feedback: the fifth session}

In the feedback session the clinician highlighted that Kiwot showed a change in his insecure-avoidant attachment pattern towards an earned secure one in the SRP. Thus the intervention was carried out to support the child's attachment behaviour, pointing out, on the one hand, the ability of Kiwot to quickly re-organize his attachment system on the basis of the new relationship with adoptive parent, and, on the other hand, the increasing maternal ability to detect and to interpret the child's physical and psychological signals, supported by the new awareness of the impact of early abandonment on the child's development. In addition, Johanna's attention was focused on the attachment narrative that emerged in Kiwot's 
MCAST, which highlighted security together with mild disorganization.

The clinician explained that Kiwot was gradually internalizing positive representations of a caregiver who is able to understand and respond to his attachment needs when they were activated, maybe thanks to ordinary sensitive and affective mother-child interaction. Otherwise, negative past experiences of loss and emotional deprivation, can be retraced in the mild disorganized indexes suggesting that fear and violence still characterized the internal attachment of Kiwot. Lastly, the clinician also highlighted that for Johanna, knowing that she can count on her husband and be sustained by him - as the secure attachment representation by the CRI revealed - gave her the ability to deal with less stress and more confidence in the difficulties inherent in the new role of adoptive parent.

\section{The long-term follow-up: after seven years}

Seven years after the last session, Kiwot and his mother were contacted again and they were glad to be involved in the follow-up. Before the interviews, Johanna completed the Life Stress Questionnaire (LSQ; adapted from Holmes \& Rahe, 1967) for highlighting what events have happened in this long period of time. None dramatic change emerged in her family life (losses, illnesses, etc.), except the voluntary reduction of her work time following the adoption.

\section{Friend and Family Interview}

The FFI administered to Kiwot, when he was 13 years old, was classified as secure indicating that the person's narrative reflects flexibility, ease and ability to turn to others for support in case of distress. Kiwot was able to provide an integrated picture of positive and negative aspects both of himself, and relationships with relevant figures, such as parents, sister, teacher and best friend. For example, he described himself pointing out both strengths and weaknesses, I am quite lively, I am bit lazy in study, very friendly and more instinctive than reflective. He talked about the relationships with his parents in a balanced, coherent and complete manner, considering them, especially his mother, as people whose love and care is always available, in other words a secure base on which to rely. In addition, Kiwot showed both openness toward emotions and good reflective functioning: he was able to capture the changes in the relationships with his parents over time and to reflect on what they think about him, highlighting good flexibility of thought. In addition, Kiwot was open to speaking about adoption: during the interview he spontaneously brought up the topic of his younger sister, Semerat, who remained in their country of origin. He was able to touch on the feelings connected with this experience of separation and he reported his concern and preoccupation with his sister. Even in this case, he recounted that his mother was able to comfort him, showing how she represented a relevant source of reassurance for the boy.

\section{Adult Attachment Interview-1}

In the follow-up AAI, Johanna was classified as free/autonomous, shifting from F4b subcategory to $F 3 b$ one, indicating the prototypical secure attachment state of mind (Table 2). This change indicated a reduction of preoccupation with attachment figure and a movement towards the exemplar group of secures who, despite their difficult experiences during childhood, are presently exceptionally thoughtful. Indeed, Johanna appeared remarkably balanced and reflective, giving the impression of being highly developed with a strong sense of self and aware of personal insecurities, fear and anxiety, in the present and childhood: My father was often aggressive without any reasons, and he got easily angry. And I think that his behaviour has generated in me a special sensitivity when I see that someone becomes aggressive both with me and others for no reason. I realized that my childhood experiences have created a weakness in me for which I have difficulty tolerating and managing certain levels of anger and aggression.

Lastly, in the second AAI the primarily unresolved loss with respect to Johanna's mother had disappeared. At the follow-up, she was able to talk about her mother's death in a much more coherent, fluid, and organized manner. In addition the lapses in the monitoring of reasoning and discourse revealed in the first AAI, namely using the present tense and falling into prolonged silences when the loss was discussed, were absent.

\section{Discussion}

The parent-child assessment and the intervention sessions described in this study had the aim to help the mother increasing her maternal sensitivity and reflecting on her attachment states of mind and their influence on the motherchild relationship. In particular, the clinician worked on enhancing Johanna's ability to perceiving and interpreting child signals and responding to these signals in an adequate and prompt way. This, in turn, could help the child's ability to turn to others for support in case of distress and to provide an integrated picture of positive and negative aspects both of himself, and relationships with relevant figures, which may have cascading effects on parent-child relationship and child's attachment representations.

As we know from the attachment literature, children who develop an insecure attachment - when living difficult situations - they do not seek comfort in the parents and their behaviours should make the task of the adoptive parents harder, even if they have a secure states of mind (Dozier \& Rutter, 2008). In line with this theoretical background, at the SRP-1 Kiwot showed an insecure-avoidant classification displaying clear attempts to minimize attachment needs and feelings. As Steele and colleagues (2007) wrote by observing the moment-to-moment interchanges between them, we can gain a window into the qualities that make the adoptive parent's task possible. 
We used the observational setting to open a window to better understand the implicit patterns of the child is to avoid seeking parents despite his need for someone who could provide help in case of emotional distress. Our intervention session may have helped the mother and child relationship at different levels: encouraging Johanna to understand the child's avoidant attachment in light of his past traumatic history, and supporting the Johanna's ability to understand the motives behind Kiwot's behaviours while connecting them to her child's attachment needs.

Further, although some studies (Juffer, BakermansKranenburg, \& Van Ijzendoorn, 2008) recommended that brief interventions should be focused just on sensitivity and mother-child attachment, this clinical intervention was also focused on maternal attachment state of mind, which is considered to strongly affect the parent-child relationship (Slade, 2010). The AAI provided evidence for the unresolved/secure mother's attachment model (U/F4b) representing that the adoptive mother's resources for emotion regulation and sensitivity were probably negatively influenced by her difficulties of getting in touch with thoughts or feelings referring to her own mother's loss. The second intervention session was focused on making the mother's lack of resolution explicit, allowing Johanna to verbalize emotions of pain and loss that she was unable to explore by herself, helping her to reflect on the meaning of her mother's loss experience.

We supposed that, in this clinical case, the maternal difficulties in the mourning process and the consequent distress activated by themes like separation and loss could be the basis of the difficulties arising when in contact with Kiwot's themes of separation and loss. Having administered the AAI at the beginning of the intervention allowed us to easily identify, face and treat this variable in a very short time. Moreover, explaining to Johanna the reason underneath the avoidant attachment behaviors of Kiwot and his mild disorganization features, probably helped her to distinguish her own difficulties from the son's ones, allowing them to live their relationships more free from the ghosts in their internal world respect to the past losses of people they loved. The second assessment, after three months, showed that Kiwot changed his attachment classification from insecure/avoidant to secure: indeed, during the task the child appeared more willing to respond to his mother signals, and the reunions were calmer and relaxed compared to the first assessment. Also the MCAST showed a secure attachment classification, with Kiwot's collaborative behaviour toward the task. Johanna was classified as secure in the CRI, reporting respect and affection for the partner and showing trust towards him.

During the feedback session, having the possibility to be contained, heard and hold by the clinician, allowed the mother to be more open in observing and reflecting on Kiwot's behaviour. The clinician reinforced the positive changes in the mother-child relationship toward a more reflective view of the child's representation of the self and the others and increasing maternal sensitivity. Observing the more positive interactions with Kiwot during the SRP2 might have allowed the mother to gain greater confidence in her ability to help and to understand the child's behaviour. Probably, when Johanna started to represent Kiwot in her mind in a more complex way, the child could have experienced a relationship with a more sensitive and accepting mother. Their more positive and affective interaction can be observed in the SRP-2 showing Kiwot's ability to internalize a positive representation of the exchanges with his adoptive mother. On the other hand, the MCAST showed the persistence of mild disorganized indexes, probably connected with early emotional deprivations. Through the clinical use of the CRI, the clinician explored Johanna's romantic relationship highlighting how the attachment security to her spouse could positively influence her style of parenting, and therefore the mother-child relationship (Busonera, San Martini, Zavattini, \& Santona, 2014).

Finally, in the follow-up Johanna revealed a prototypical secure attachment state of mind and a resolution with respect to her mother's loss, talking about her losses, with a lesser extent of sadness and pain that she had previously expressed. Kiwot showed a secure attachment representation in the FFI, characterized by an integrated picture of his adoptive parents, sister, teacher, best friend and himself, and expressed through a coherent and balanced discourse style and good reflective functioning. Surprisingly Kiwot confirmed his earned' security in adolescence, a period of great challenges for adopted adolescents demanding them to review their own identity in light of their harsh past history (Pace et al., 2015a).

\section{Conclusions}

In conclusion, this single case study supported the natural significant contribution of the new attachment relationship in modifying the adopted child's attachment pattern toward greater security, the powerful influence of adoption as a form of intervention. It also opens the way to the question how much an intervention targeting adoptive families in the first months after the adoption can help in itself (Steele et al., 2008). However, this study showed several limitations as consequence that only the mother was included in this intervention. First of all, in line with the growing literature highlighting the relevance of the father's role in the child's development and the mother's support even in studies on adoptive families, it would have been important directing the intervention also to the father (Di Folco \& Zavattini, 2014; Salcuni et al., 2015). Second, it would have been important including the child in the intervention program, not only in the assessment, according to the recent evidence suggesting the usefulness of addressing both to the child and the mother in briefterm interventions (Juffer et al., 2008). Third, observed changes should be read in light of other environmental aspects, such as the relationships with peers, which in liter- 
ature seem especially important in adolescence (Schoenmaker et al., 2015a).

\section{References}

Ainsworth, M., Blehar, M., Waters, E., \& Wall, S. (1978). Patterns of attachment: Observations in the strange situation and at home. Hillsdale, MI: Erlbaum.

Allen, B., Timmer, S.G., \& Urquiza, A.J. (2014). Parent-child interaction therapy as an attachment-based intervention: Theoretical rationale and pilot data with adopted children. Children and Youth Services Review, 47(3), 334-341. doi: 10.1016/j.childyouth.2014.10.009

Bakermans-Kranenburg, M.J., van Ijzendoorn, M.H., \& Juffer, F. (2003). Less is more: Meta-analysis of sensitivity and attachment interventions in early childhood. Psychological Bulletin 129(2), 195-215. doi: 10.1037/0033-2909.129.2.195

Barone, L., \& Lionetti, F. (2012). Attachment and emotional understanding: a study on late-adopted pre-schoolers and their parents. Child: Care, Health and Development, 38(5), 690696. doi: 10.1111/j.1365-2214.2011.01296.x

Barone, L., Del Giudice, M., Fossati, A., Manaresi, F., Perinetti, B.A., Colle, L., \& Veglia, F. (2009). Methods \& measures. Psychometric properties of the Manchester Child Attachment Story Task: An Italian multicentre study. International Journal of Behavioral Development, 33(2), 185-190. doi: 10.1177/0165025409103134

Beijersbergen, M.D., Juffer, F., Bakermans-Kranenburg, M.J., \& van IJzendoorn, M.H. (2012). Remaining or becoming secure: Parental sensitive support predicts attachment continuity from infancy to adolescence in a longitudinal adoption study. Developmental Psychology, 48(5), 1277-1282. doi: $10.1037 / \mathrm{a} 0027442$

Bimmel, N., Juffer, F., van IJzendoorn, M.H., \& Bakermans-Kranenburg, M.J. (2003). Problem behavior of internationally adopted adolescents: A review and meta-analysis. Harvard Review of Psychiatry, 11(2), 64-77. doi: 10.1080/1067322030 3955

Busonera, A., San Martini, Zavattini, G.C., \& Santona, A. (2014) Psychometric properties of an Italian version of the experiences in close relationships-revised (ECR-R) scale. Psychological Reports, 114 (3), pp. 785-801

Carnes-Holt, K. (2012). Child-parent relationship therapy for adoptive families. The Family Journal, 20(4), 419-426. doi: $10.1177 / 1066480712451242$.

Cassidy, J. (1988). Child-mother attachment and the self in sixyear-olds. Child Development, 59(1), 121-134. doi: 10.2307/ 1130394

Crowell, J.A., \& Owens, G. (1996). Current Relationship Interview and scoring system. Stony Brook, NY: State University of New York.

Di Folco, S., \& Zavattini, G.C. (2014). La relazione d'attaccamento padre-bambino: una rassegna della letteratura $[\mathrm{Fa}-$ ther-child attachment relationship: A review of the literature]. Giornale Italiano di Psicologia, 41(1), 159-190. doi: $10.1421 / 77211$

Dozier, M., \& Rutter, M. (2008). Challenges to the development of attachment relationships faced by young children in foster and adoptive care. In: J. Cassidy, \& P.R. Shaver (Eds.) Handbook of attachment: Theory, research, and clinical applications (pp. 698-717). New York, NY: Guilford Press.
Dozier, M., Grasso, D., \& Lindhiem, O. (2007). The role of caregiver commitment in foster care: Insights from the This Is My Baby Interview. In D. Oppenheim, \& D. Goldsmith (Eds.) Attachment theory in clinical work with children: Bridging the gap between research and practice (pp. 90108). New York, NY: Guilford Press.

Dozier, M., Peloso, E., Lindhiem, O., Gordon, M.K., Manni, M., Sepulveda, S., ..., \& Levine, S. (2006). Developing evidence-based interventions for foster children: an example of a randomized clinical trial with infants and toddlers. Journal of Social Issues, 62(4), 767-785. doi: 10.1111/j.1540-4560. 2006.00486

Goldberg, A.E., \& Smith, J.Z. (2014). Predictors of parenting stress in lesbian, gay, and heterosexual adoptive parents during early parenthood. Journal of Family Psychology, 28(2), 125-137. doi:10.1037/a0036007

Goldsmith, D.F. (2007). Challenging children's negative internal working models: Utilizing attachment based strategies in a therapeutic preschool. In: D. Oppenheim, \& D. Goldsmith (Eds.) Attachment theory in clinical work with children: Bridging the gap between research and practice (pp. 203225). New York: Guilford Press.

Green, J., Stanley, C., Smith, V., \& Goldwyn, R. (2000). A new method of evaluating attachment representations in young school-age children: The Manchester Child Attachment Story Task. Attachment \& Human Development, 2(1), 4870. doi: $10.1080 / 146167300361318$

Grotevant, H.D., \& McDermott, J.M. (2014). Adoption: Biological and social processes linked to adaptation. Annual Review of Psychology, 65, 235-265. doi: 10.1146/annurevpsych-010213-115020

Gurney-Smith, B., Granger, C., Randle, A., \& Fletcher, J. (2010). In time and in tune. The Fostering Attachments Group. Capturing sustained change in both caregiver and child. Adoption \& Fostering, 34(4), 50-60. doi: 10.1177/ 030857591003400406

Holmes, B., \& Silver, M. (2010). Managing behaviour with attachment in mind. Adoption \& Fostering, 34(1), 65-76. doi: 10.1177/030857591003400107

Holmes, P., \& Farnfield, S. (2014). The Routledge handbook of attachment: Implications and interventions. London-New York, UK-NY: Routledge.

Holmes, T., \& Rahe, R. (1967). The social readjustment rating scale. Journal of Psychosomatic Research, 11(2), 213-218.

Howe, D. (1998). Adoption outcome research and practical judgment. Adoption \& Fostering, 22(2), 6-15. doi: 10.1177/ 030857599802200203

Italian Adoption Commission (2014). Dati e prospettive nelle adozioni internazionali: Rapporto della Commissione per le Adozioni Internazionali sui Fascicoli dal $1^{\circ}$ Gennaio al 31 Dicembre 2013. Available from: http://www.commissioneadozioni.it/media/143019/report_statistico_2013.pdf

Juffer, F., Bakermans-Kranenburg, M.J., \& Van IJzendoorn, M.H. (2005). The importance of parenting in the development of disorganized attachment: evidence from a preventive intervention study in adoptive families. Journal of Child Psychology and Psychiatry, 46(3), 263-274. doi: 10.1111/ j.1469-7610.2004.00353.x

Juffer, F., Bakermans-Kranenburg, M.J., \& van IJzendoorn, M.H. (2008) Enhancing children's socioemotional development: A review of intervention studies. In D.M. Teti (Ed.) Handbook of research methods in developmental science (pp. 213-232). Oxford, UK: Blackwell Publishing Ltd. doi: 10.1002/9780470756676.ch11 
Kerr, L., \& Cossar, J. (2014). Attachment interventions with foster and adoptive parents: A systematic review. Child Abuse Review, 23(6), 426-439. doi: 10.1002/car.2313

Lionetti, F., Pastore, M., \& Barone, L. (2015). Parenting stress: the roles of attachment state of mind and parenting alliance in the context of adoption. Parenting Science Practice, 15, 75-79. doi: 10.1080/15295192.2015.1020142

Main, M., \& Cassidy, J. (1988). Categories of response to reunion with the parent at age 6: predictable from infant attachment classifications and stable over a 1-month period. Developmental Psychology, 24(3), 415-426. doi: 10.1037/ 0012-1649.24.3.415

Main, M., Goldwyn, R., \& Hesse, E. (2002). Adult attachment scoring and classification system. Berkeley, CA: Department of Psychology, University of California.

Main, M., Hesse, E., \& Goldwyn, R. (2008). Studying differences in language usage in recounting attachment history: An introduction to the AAI. In H. Steele, \& M. Steele (Eds.) Clinical applications of the Adult Attachment Interview (pp. 31-68). New York, NY: Guilford Press.

Oppenheim, D., \& Goldsmith, D. (2007). Attachment theory in clinical work with children: Bridging the gap between research and practice. New York, NY: Guilford Press.

Pace, C.S. (2014). Assessing attachment representations among adoptees during middle childhood and adolescence with the Friend and Family Interview (FFI): clinical and research perspectives. Frontiers in Psychology, 5, 1114. doi: 10.3389/ fpsyg.2014.01114

Pace, C.S., \& Zavattini, G.C. (2011). 'Adoption and attachment theory' the attachment models of adoptive mothers and the revision of attachment patterns of their late-adopted children. Child: Care, Health and Development, 37(1), 82-88. doi: 10.1111/j.1365-2214.2010.01135.x

Pace, C.S., Cavanna, D., Velotti, P., \& Zavattini, G.C. (2014). Attachment representations of late-adopted children through attachment narratives: an assessment of disorganisation mentalising and coherence of mind for adoption practice. Adoption \& Fostering, 38(3), 255-270. doi: 10.1177/ 030857591454323510.1177/03085759145432

Pace, C.S., Di Folco, S., Guerriero, V., Santona, A., \& Terrone, G. (2015a). Adoptive parenting and attachment: association of the internal working models between adoptive mothers and their late-adopted children during adolescence. Frontiers in Psychology, 6, 1433. doi: 10.3389/fpsyg.2015.01433

Pace, C.S., Santona, A., Zavattini, G.C., \& Di Folco, S. (2014). Gli stati della mente rispetto all'attaccamento al caregiver e al partner di coppie nell'assessment preadottivo. [Attachment states of mind with respect to attachment to the caregiver and the partner of couples during pre-adoption assessment]. Giornale Italiano di Psicologia, XLI(2), 347-364. doi: 10.1421/77908

Pace, C.S., Santona, A., Zavattini, G.C., \& Di Folco, S. (2015b). Attachment states of mind and couple relationships in couples seeking to adopt. Journal of Child and Family Studies, 24(11), 3318-3330. doi: 10.1007/s 10826-015-0134-6

Pace, C.S., Zavattini, G.C., \& D’Alessio, M. (2012). Continuity and discontinuity of attachment patterns: A short-term longitudinal pilot study using a sample of late-adopted children and their adoptive mothers. Attachment \& Human Development, 14(1), 45-61. doi: 10.1080/14616734.2012.636658

Pace, C.S., Zavattini, G.C., \& Tambelli, R. (2015). Does family drawing assess attachment representations of late-adopted children? A preliminary report. Child Adolescent Mental Health, 20(1), 26-33. doi: 10.1111/camh.12042

Palacios, J., \& Brodzinsky, D. (2010). Adoption research: trends, topics, outcomes. International Journal of Behavioral Development, 34(3), 270-284. doi: 10.1177/0165025410362837

Salcuni, S., Di Riso, D., \& Lis, A. (2014). “A child's nightmare. Mum comes and comforts her child." Attachment evaluation as a guide in the assessment and treatment in a clinical case study. Frontiers in Psychology, 5. doi: 10.3389/fpsyg.2014. 00912

Salcuni, S., Miconi, D., Altoè, G., \& Moscardino, U. (2015). Dyadic adjustment and parenting stress in internationally adoptive mothers and fathers: the mediating role of adult attachment dimensions. Frontiers in Psychology, 6. doi: 10.3389/fpsyg.2015.01279

Schoenmaker, C., Huffmeijer, R., van IJzendoorn, M.H., Bakermans-Kranenburg, M.J., van den Dries, L., Linting, M., ..., \& Juffer, F. (2015b). Attachment and physiological reactivity to infant crying in young adulthood: Dissociation between experiential and physiological arousal in insecure adoptees. Physiology \& Behavior, 139, 549-556. doi: 10.1016/j.physbeh.2014.11.055

Schoenmaker, C., Juffer, F., van IJzendoorn, M.H., Linting, M., van der Voort, A., \& Bakermans-Kranenburg, M.J. (2015a). From maternal sensitivity in infancy to adult attachment representations: a longitudinal adoption study with secure base scripts. Attachment \& Human Development, 17(3), 241-246. doi: $10.1080 / 14616734.2015$

Slade A. (2010). Relazione genitoriale e funzione riflessiva. Teoria, clinica e intervento sociale. [Parental relationship and reflective functioning. Theory, clinic and social intervention]. Roma: Casa Editrice Astrolabio.

Steele, M., Hodges J., Kaniuk, J., Steele, H., D’Agostino, D., Blom, I., Hillman, S., \& Henderson, K. (2007). Intervening with maltreated children and their adoptive families. Identifying attachment-facilitative behaviors. In D. Oppenheim, \& D.F. Goldsmith (Eds.) Attachment theory in clinical work with children: Bridging the gap between research and practice (pp. 58-89). New York, NY: Guilford Press.

Steele, H., \& Steele, M. (2008). Clinical applications of the Adult Attachment Interview. New York, NY: Guilford Press.

Steele, M., Hodges, J., Kaniuk, J., Steele, H., Hillman, S., \& Asquith, K. (2008). Forecasting outcomes in previously maltreated children: The use of the AAI in a longitudinal adoption study. In H. Steele, \& M. Steele (Eds.) Clinical applications of the adult attachment interview (pp. 427-451). New York, NY: Guilford Press.

Steele, H., Steele, M., \& Kriss, A. (2009). The friends and family interview (FFI) coding guidelines. New York, NY: The New School for Social Research.

van den Dries, L., Juffer, F., van IJzendoorn, M.H., \& Bakermans-Kranenburg, M.J. (2009). Fostering security? A metaanalysis of attachment in adopted children. Children and Youth Services Review, 31(3), 410-421. doi: 10.1016/j. childyouth.2008.09.008

van der Voort, A., Linting, M., Juffer, F., Bakermans-Kranenburg, M.J., \& van IJzendoorn, M.H. (2013). Delinquent and aggressive behaviors in early-adopted adolescents: Longitudinal predictions from child temperament and maternal sensitivity. Children and Youth Services Review, 35(3), 439446. doi: 10.1016/j.childyouth.2012.12.008

van der Voort, A., Linting, M., Juffer, F., Bakermans-Kranenburg, M.J., Schoenmaker, C., \& van IJzendoorn, M.H. (2014). The development of adolescents' internalizing behavior: Longitudinal effects of maternal sensitivity and child inhibition. Journal of Youth and Adolescence, 43(4), 528540. doi: 10.1007/s10964-013-9976-7 